\title{
TEACHER KNOWLEDGE STRUCTURE OF PHYSICS TEACHERS
}

\author{
Haibin Sun \\ College of Physics and Electronic Engineering \\ Taishan University, Tai'an City, China 271000
}

\begin{abstract}
Teacher knowledge plays an important role in the physics curriculum reform process. In order to cultivate excellent physics teachers, it is necessary to clarify the connotation of teacher knowledge structure. Physics teacher knowledge is the premise of teachers to work on education. Teacher knowledge structure directly affects the teaching quality of physics teachers. Teacher knowledge structure is directly related to the professional development level of physics teachers. Perfect teacher knowledge structure is a prerequisite for teachers' professional development. The physics teacher's teacher knowledge structure includes knowledge of physics subject, knowledge of relevant subjects, knowledge of pedagogy subject, and information technology.
\end{abstract}

Keywords- Teacher Knowledge structure, Physics teacher, Teacher professional development

\section{INTRODUCTION}

The education reform of American teachers in the 20th century is mainly featured with non-directional, open and phased. Students learn the content knowledge in basic college of arts and sciences; and then they learn professional pedagogical knowledge in the education college. However, in the process of teacher professionalization, the pedagogical knowledge and subject professional knowledge are separate $[1,2]$.

The effect of this separate teacher education model is unsatisfactory. Because the teacher's teaching level is still difficult to improve after mastering a large amount of subject knowledge and educational knowledge. The difference between teaching and non-teaching staff in teaching practice is not obvious. Obviously, the knowledge base of professional teachers is still not established. On the view of it, a group of researchers headed by American scholar L. Shulman has tried to seek for the foundation of professional knowledge of teachers since the mid-1980s [3-5]. The knowledge categories needed by the teaching is clarified and the concept of pedagogical content knowledge (PCK) is also suggested.

Excellent physics teachers must have a composite, complete, and developing teacher knowledge structure [6-8]. This paper focuses on the teacher knowledge structure of physics teachers.

\section{Teacher KNOWLedge AND TeACHER KNOWLEDGE STRUCTURE}

After the 1970s, traditional knowledge view has been challenged. People come to realize that education is changeable and dynamic process. This process involves a variety of uncertain, contextual factors. As a complicated teaching of complex cognitive activities, the teaching effect and quality greatly depends on the knowledge owned by the teachers under specific situation.

\section{A. Teacher Knowledge}

Knowledge is the main content and carrier of education. The process of education is actually the process, in which teachers choose knowledge, organize knowledge, present knowledge and impart knowledge. At the same time, teachers create conditions to help students master knowledge, understand knowledge, practice knowledge and explore knowledge. Based on these, the comprehensive development of students could be promoted. Teacher knowledge is a general name of a series of understanding, knowledge and skills owned by teachers in order to achieve effective teaching in the actual teaching situation. Teacher knowledge is the premise of teachers to work on education.

In different literature, teacher knowledge is usually divided into different facets [9]. L. Shulman (1987, 1986) believes that the basic knowledge of teachers includes[3, 4]:

(1) Content knowledge, including content knowledge such as specific concepts and rules; entity knowledge such as paradigms within disciplines; syntactic knowledge such as interdisciplinary connections;

(2) General pedagogical knowledge, , with special reference to those broad principles and strategies of classroom management and organization that appear to transcend subject matter;

(3) Curriculum knowledge, meaning the teaching media and teaching plan proficiency;

(4) Pedagogical content knowledge, that distinguishes teachers from other subject specialists, and to specifically teach specific knowledge of the content to be taught;

(5) Knowledge of learners and their characteristics, including knowledge of individual development and individual differences of students; 


\section{International Journal of Engineering Applied Sciences and Technology, 2019 \\ Vol. 4, Issue 3, ISSN No. 2455-2143, Pages 55-61 \\ Published Online July 2019 in IJEAST (http://www.ijeast.com)}

(6) Knowledge of educational contexts, including the status of activities of groups or classes, characteristics of community and regional culture;

(7) Knowledge of educational ends, purposes, and values, and their philosophical and historical grounds.

In these categories, PCK has special significance because it determines the unique body of knowledge in teaching. It represents a fusion of content and pedagogy to understand how a particular topic, question or problem is organized, expresses and adapts to the different interests and abilities of the learner, and provides it to teaching.

\section{$B$. Teacher knowledge structure}

The structure of teacher knowledge directly affects the teaching quality of teachers. It is also a premise of teachers' professional development and it is also necessary condition for teachers to have effective teaching. The opinions and points of scholars at home and abroad on the structure of teachers' knowledge are not exactly the same, but they normally think that there should be at least three parts in the structure: professional knowledge, basic knowledge of science and culture and knowledge of pedagogy and psychology [10, $11]$.

Xin Tao, Lin Chongde and Shen Jiliang (1999) [12]points out that teaching activity is a cognition activity. As a foundation of teacher's cognition activity, teachers' knowledge could be divided into four types from the functions: subject-matter knowledge, conditional knowledge, practical knowledge and cultural knowledge. These four aspects form the structure of teachers' knowledge.

(1) Subject-matter knowledge means the specific subject knowledge owned by teachers, such as the knowledge of Chinese and mathematics. It is a teacher knowledge that is familiar with people. The consolidated subject-matter knowledge of teachers is a basic promise to the better teaching effect.

(2) Conditional knowledge means the knowledge of pedagogy and psychology owned by teachers. It is an important guarantee of a successful teaching of teachers, and it mainly includes the knowledge of students' physics and mental development, knowledge of teaching and learning and knowledge of students' performance evaluation.

(3) Practical knowledge means the situational knowledge in classroom and related knowledge owned by teachers to realize purposeful behavior, which would be accumulated from teaching experience. Practical knowledge is affected by persona experience and the experiences are cumulative effect of human intention and purpose and life experience. So, there are abundant details in the expression of the knowledge, and it is exited with individualized language.

(4) Cultural knowledge. In order to realize the cultural function of education, teachers must have extensive knowledge of culture in addition to the above three kinds of knowledge, so as to lead students to the future of life. Teachers can not only expand the spiritual world of students, but also stimulate their curiosity. The overall development of students depends to a certain extent on the breadth and depth of the cultural knowledge of teachers.

\section{KNOWledge StRUCTURE OF PHYSICS TEACHER}

Mervi A. Asikainen and Pekka E. Hirvonen (2010) [13] studied the knowledge base of the physics teacher education at master's level in University of Eastern Finland, the results pointed out that physics teacher's teacher knowledge can be divided into a knowledge of physics and a knowledge of the teaching of physics.

Heidi Krzywacki et al. (2017) [14] established a simple model of physics teacher knowledge; the model divides physics teacher knowledge into three categories. (1) Content (subject matter) knowledge constitutes a knowledge domain related to expertise in a particular subject, such as physics. It includes conceptual and procedural knowledge in the given domain. Furthermore, a teacher needs to understand the nature of knowledge - that is, the epistemological and ontological aspects of the subject. However, content knowledge is not the focus of this research. (2) Pedagogical content knowledge is a knowledge domain that distinguishes teachers from other subject specialists. PCK is the synthesis of all knowledge needed for the teaching and learning of a certain topic. (3) General pedagogical knowledge (GPK), general pedagogical knowledge consists of the following general knowledge areas related to pedagogy: classroom management and organization, instructional models and strategies, and classroom communication and discourse.

We think that the teacher knowledge structure of physics teachers should be composed with four parts, including knowledge of physics subject, knowledge of relevant subjects, knowledge of pedagogy subject, and information technology.

\section{A. Knowledge of physics subject}

As to physics teachers of middle school, it is very necessary for them to master systemic and complete physics knowledge. The knowledge of physics subject should be basic knowledge of physics, history of physics, methodology of physics, development trend and application of physics.

(1) Basic knowledge of physics

Physics is a basic subject of natural science since it studies the basic structure, interaction and motion law of matter in nature. Based on observation and experiment, the physics models and applied mathematics such tools are built up. Through the scientific reasoning and argumentation, the systemic research methods and theory systems are formed in the subject. From natural philosophy in ancient Greece to classical physics in the 17 th and 18 th centuries and to relativity and quantum theory in modern times, physics has always led the exploration of the mysteries of nature and to deepen humans' knowledge to the nature. Physics imposes great impact on chemistry, life science, earth and universe science and other natural science. And it promotes the progress of science and technology in material, energy, 


\section{International Journal of Engineering Applied Sciences and Technology, 2019 \\ Vol. 4, Issue 3, ISSN No. 2455-2143, Pages 55-61 \\ Published Online July 2019 in IJEAST (http://www.ijeast.com)}

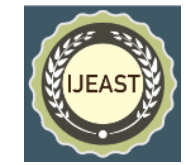

environment and information, so as to push the transformation of human production and lifestyle. What's more, there is also great impact on the human's way of thinking and values. It makes a great contribution to human civilization and social progress [15] .

The basic knowledge of physics includes the basic facts, concepts and rules of physics and their relations. Physics teachers must have extensive and accurate understanding on these basic knowledges since teachers could not teach some inaccurate or wrong things to students. There is another important reason that teachers could spend much time and energy to focus on the development of students with the basis of the grasp of knowledge, instead of just clarifying what they are teaching.

(2) Knowledge and skills of physics experiment

Physics is a science based on experiment. The experiment foundation, theoretical system and research methods are the basis of modern science and technology. From the principle of the equivalence of acceleration, inertia and pendulum and the relativity of discovering motion established by the pioneer of experimental physics, Galileo, to the establishment of the electromagnetic field theory of a theoretical physicist, Maxwell, are proved by experiment. The classical physics could not live without physics experiment, so does the modern one. The new theories and inventions of physics could not live without experiment, neither. And all of these should be owed to the efforts of theoretical physicists and experimental physicists. Currently, such scientific technologies as space technology, modern communication technology, laser technology, electronics and computer technology and biotechnology could not live without experiment.

Physics experiment is one important composition of physics course and physics teaching. It is foundation of physics teaching and it is also important content. Physics thoughts, facts, principles and conclusions are shown through experiment. The teaching of physics concepts and rules could not live without experiment. Physics experiment is a key role in the cultivation of students' ability of observation, thinking analysis, experimental operation, conclusion and application as well as creation.

Physics teachers should not only master the experiment principal, experiment design thinking and methods, and they should also be equipped with skillful experiment operation. Physics teachers should be familiar with the purpose, steps, structure, and use of instruments, operational skills, measurement data and processing for each experiment in textbooks. What's more, they should also master principle of instrument mechanism, and they should learn the troubleshooting. Along with the rapid development of modern technology, the teaching devices and experimental methods are upgrading, which requires that physics teachers must grasp and apply new instruments and methods.

Physics teachers should not only be proficient these and they should guide students to have grouping experiment and demonstration with the equipment in the lab. Teachers should have experiment similar with the one in the textbook with the objects in their life or the self-made teaching tools, so as to cultivate the lifetime experiment passion of teachers. They could be shaped with lifetime habit of doing experiment. Selfmade teaching tool is a basic skill of teachers. Teachers with experience and ability could modify or make some teaching tools according to the teaching need. They would also satisfy the teaching demand with substitute products to improve the teaching effect.

(3) History of physics

History of physics is a subject to study the development of physics. It is important composition in the system of physics, and it is important role in the teaching of physics teachers. Teachers could cultivate students' scientific consciousness, spirit and method by teaching the knowledge of history of physics. The educational function of physics is mainly these two parts. First is to make students to know the thinking process and scientific research methods in the finding of rules. Abundant materials of history of physics are providing in the teaching process, so as to show the historical development of physics concepts and rules to students. Therefore, they could know the thinking process and scientific research methods and they could be inspired form the failures and success of scientists. Students could be influenced by scientific thinking methods through the education of history of physics and they could know how scientists use scientific methods to conduct research, which is good for students to transfer from passive accepting study to the exploring learning. The second one is to cultivate students' science awareness and science sprite. Physics is the science of studying the general rules of material movement and the basic structure of matter, and it is important composition of natural science. Through the education of history of physics, students could be cultivated with scientific consciousness of seeking truth from facts and strict scholarship. Some major inventions or vivid examples of scientific discovery should be introduced to arouse the respect of students to scientists, so that they could be cultivated with realistic and rigorous scientific consciousness and innovative scientific spirit.

To effectively play the educational function of history of physics, physics teachers should have higher quality of the history. Improving the quality of learning history is of great significance for teachers to comprehensively understand and grasp the knowledge system of physics and to improve the teaching level.

(4) Methodology of physics

Methodology of physics is important composition in the system of physics learning and it is also necessary part of the knowledge qualification of physics teachers. In the development of physics, each updating of scientific methods of physics symbolizes the major development of physics. Hence, it is important to master physics if you know nothing about the methods of physics or the application of these methods. Besides, scientific methods of physics are in 
important education value. The common study methods of middle school students are not only important part for physics learning and there is also great benefit for the further education and creation jobs of college students after graduation.

The methodology of physics is mainly included common methods (observational experiments, analysis and synthesis, comparison and classification, induction and deduction, analogy, idealization, hypothesis, mathematical methods, cybernetics, system theory, information theory, synergy theory and so on) and uncommon methods (intuition and Inspiration, opportunity, scientific imagination and conjecture, physics aesthetics, errors and fallacies, etc.).

(5) Frontier knowledge in physics

Physics is a subject filled with energy and vitality. The development is daily changing. For a physics teacher in middle school, it is very important to know the latest development of physics and the impact on social life as well as knowing the undertaking researches and the latest progress. It is pointed in the compulsory education physics curriculum standard that students should know the mutual relationship between natural thinks, paying attention to the connection and penetration among subjects, focusing on the new development of scientific technology and the impact of technology development on the social progress, so as to form a correct view of world. One of curriculum basic concepts given by the high school physics is to focus on the timeliness of course and the demand of technology progress and social development. The physics courses in high schools think highly of the linkage between production life, modern society and technology development, so as to reflect the important harvests and scientific thinking of current technology development. At the same time, it also focuses on the social problems brought by the technology application of physics, so as to cultivate the students' social participation consciousness and social responsibility.

Various versions of the new textbooks for middle school physics have added knowledge content that is closely related to modern science and technology and social development. Compared with traditional textbooks, the content of the new physics textbooks expands the scope of the original knowledge. Teachers should not only be familiar with the knowledge given in books, but also understand the development trend of physical science, practical application and social development and society. All of these require the teachers to keep tracing the advancing development of the subject. According to the tendency of the development, the fixed knowledge structure is changed to adapt to the requirement of the new situation.

\section{$B$. Knowledge of relevant subjects}

Among the natural science courses in middle schools, physics is the subject with the strongest comprehension, practice and thinking. It is involved with all regions of natural science, so physics teachers should be equipped with abundant knowledge of relevant subjects besides the professional knowledge of physics. The importance of physics teachers mastering mathematical knowledge goes without saying. Physics is a quantitative subject with the tool of mathematics. Mathematics is a Language tool to express physics contents and it is also the tool to have logical deduction and quantitative calculation. The expression and reasoning and argumentation of physics' concepts and rules are hard to done without the tool of mathematics. Mathematics tool is a critical role in the physics teaching in middle schools.

Apart from mathematics, the knowledge of other subjects is also critical. For the development of modern science technology, mutual penetration and integration of knowledge in various disciplines has been strengthened day by day. The subjects are mutually involved for the longitudinal branch and transverse synthesis of subject knowledge, so physics teachers should adjust to the development tendency and they should learn some knowledge of other subjects to enrich their knowledge, instead of being satisfied with the narrow range of their major. When physics teachers have extensive and profound basic knowledge of cultural science, they can provide chances for students to gain much more knowledge, finding students with special talents timely and organically combining the physics with other subjects.

The interdisciplinary comprehensive knowledge is added in the new courses to emphasize the course integration, communication and integration among subjects. Course integration is a design thinking and principal which means to emphasize the linkages and consistency among subjects so as to avoid the early or excessive emphasis on the distinctions and boundaries of various disciplines and to prevent from the isolation among subjects. Under the guidance of the course integration, the new teaching materials of all subjects do think highly of the mutual communication and comprehension. However, the teachers cultivated by the traditional normal education system are in imbalanced quality structure, too much professional knowledge and insufficient comprehensive quality, which mean that teachers of all subjects should think less of their own subject and supplement knowledges of other related subjects.

Under the circumstance, physics teachers should change their original opinions that they just teach students with physics knowledge as a physics teacher. For the rapid development of information technology, the way for students to gain information is increasing and they would ask teachers various kinds of problems. Some of them are the comprehensive and they could not be fixed with the knowledge of one subject. Teachers should be involved with other subjects so as to prevent from the unfavorable phenomena in the teaching.

\section{Knowledge of pedagogy subject}

Physics teacher should be qualified with teaching jobs, which requires teachers to have abundant knowledge of pedagogy and psychology besides mastering professional knowledge of 
physics. The role of these knowledges is that teachers could accurately explain the behaviors and words of students and guides them properly when they are in need. As a result, this knowledge could greatly help teachers to perform their professional jobs. These knowledges are called as professional knowledge of pedagogy. The professional knowledge of pedagogy needed by physics teachers could be divided into two types, normal pedagogy knowledge and physics pedagogy knowledge.

\section{(1) General pedagogy knowledge}

The range of normal pedagogy knowledge is so extensive. There are including knowledge of pedagogy, including basic theory of pedagogy, research methods of pedagogic science and history of education, and knowledge of psychology, such as basic theory of psychology, educational psychology, developmental psychology and cognitive psychology.

As a physics teacher, the following knowledge of psychology knowledge should be mastered:

General psychology. The basic knowledge of psychology and some basic psychological phenomenon could be learned through it, so as to roughly understand and master the subject of psychology.

Developmental psychology. The stipulation of curriculum standard of all subjects is based on the development psychology. Teachers should know the law of students' psychological development, psychology characters of each aging periods and the individual difference in the process of psychology development.

Pedagogic psychology. The core of pedagogic psychology is to study the problem of students, including the way to learn, learning habits and learning strategies. Abundant pedagogic psychology is good for teachers to fix the psychological problems that students meet in the learning process.

Besides, knowledge of social psychology, counseling psychology and mental health education are very useful. Teachers could selectively supply psychology knowledge according to the own situation. Knowing much more of psychology knowledge is not only beneficial for the teaching and it is also good for teachers to maintain healthy psychology. It is very necessary to shape a better psychology quality.

(2) Physics pedagogy knowledge

As an excellent physics teacher, the rules and methods of physics pedagogy knowledge must be mastered. The physics pedagogy knowledge that physics teachers should master should be physics teaching method, physics teaching theory, physics curriculum theory, physics educational psychology, physics learning psychology, physics education research methodology, physics teaching art, physics teaching design. Shulman thinks that PCK is a knowledge system to identify teachers and other intellectual people. He suggests that pedagogical content knowledge is to infuse the content and teaching to be an understanding with teachability; teachers know how to organize, express and adjust teachers' own subject knowledge according to students' different interests and abilities on a particular topic, question or topic, and teach them.

\section{Knowledge of Information Technology}

21 st century is an age of information. Computer and other information technology are in rapid development and they are widely applied into all regions of human society and all aspect of their life, so as to be necessary part of human life. The development of information technology greatly changes the way of people to gain information, the way to express them and the way to carry out social activity. Information quality has been important composition of citizen quality. There must be certain information quality in the knowledge structure of physics teachers since it stands for the degree of people mastering information technology. The information quality includes ability to use information technology tools; ability to actively obtain information; ability to retrieve, organize, use, transmit and exchange information; good sense of cooperation and cooperation; ability of information immunity and information ethics; ability to use acquired information for problem solving and creative thinking activities. Physics teachers should make the information technology as a tool of lifetime learning and cooperation study to improve their information quality gradually.

Physics teachers should be equipped with sensitive information awareness and good information ability. Besides, they should be proficient in the usage of information tools to create visualized physics scenarios with information technology, and to build up physics teaching based on network, and to combine the physics virtual teaching and practical teaching. Physics teaching based on information technology should be in balanced development in the infusion of the virtual teaching and practical teaching. The development of information quality of physics teacher could be developed with the basis of practical experience and the combination of virtual teaching.

By far, the combination of artificial intelligence (AI) and education could make education information a further progress, intelligent education phase [16]. The role of physics teachers with the support of AI in the future would be changed. The intellectual teaching role of teachers will be replaced by AI while the blinding role of teachers will be more and more important. Physics education will go to the future time of the cooperation of teachers and AI. The future education will be in the time of co-existence of physics teachers and AI. Physics teachers and AI will play their own role to cooperate with each other so as to realize individual and inclusive education and lifetime and equal education, so as to promote the comprehensive development of students .

Traditionally, the job of physics teachers could be divided into two parts, the creative job with the representative of teaching design and emotional communication and the mechanically repeating jobs such as homework checking and feedback, while the source of teachers' stress is from the later. The advantage of $\mathrm{AI}$ is to learn the regulations of repeating 


\section{International Journal of Engineering Applied Sciences and Technology, 2019 \\ Vol. 4, Issue 3, ISSN No. 2455-2143, Pages 55-61 \\ Published Online July 2019 in IJEAST (http://www.ijeast.com)}

things based on data to deal with these tasks high-efficiently and accurately. In the time of AI, there will be a great change in the work status of physics teachers. The intellectual teaching job will be undertaken by AI while teachers just take responsibility on the design of learning, supervision, incentives and accompaniment. Much of the job would be the emotional communication with students and cultivating students. In the future cultivation environment, there is environment combined with the virtuality and the reality with the support of AI, which is the combination of online and offline. There are thousands of learning services and different AI supports the free combination of students. Teachers will take a different role, such as learning service design, learning accompaniment, emotional incentives, diagnosis and improvement of learning problems, career development planning of learning guidance, planning and design of social activities. The main working status of physics teachers will be in substantive changes. The work of physics teachers in the future will be the following, design and development of learning service, individual learning guidance; comprehensive learning activity organization; connection of social network; diagnosis and improvement of learning problems,, management and counseling of psychological health, physics health monitoring and improvement; guidance of beliefs and values; developmental assessment and improvement; guidance of career development planning; professional growth of peer-to-peer aiding; decision-making of manmachine education; ethical supervision of AI education services.

\section{CONCLUSIONS}

Knowledge is the main content and carrier of education. Physics teacher knowledge is the premise of teachers to work on education. Teacher knowledge structure directly affects the teaching quality of physics teachers. Perfect teacher knowledge structure is a prerequisite for teachers' professional development. The physics teacher's teacher knowledge structure includes knowledge of physics subject, knowledge of relevant subjects, knowledge of pedagogy subject, and information technology.

\section{ACKNOWLEDGEMENT}

The research is supported by the Teaching Reform Project of Taishan University (201836).

\section{REFERENCE}

[1]Donnelly, D. F. \& Boniface, S. (2013). Consuming and creating: Early-adopting science teachers' perceptions and use of a wiki to support professional development. Computers \& Education, vol. 68, (pp. 9-20).

[2]Hanuscin, D. L. (2017). Critical incidents in the development of pedagogical content knowledge for teaching the nature of science: A prospective elementary teacher's journey. Journal of Science Teacher Education, vol. 24, No. 6, (pp. 933-956).

[3]Shulman, L. (1987). Knowledge and teaching: Foundations of the new reform. Harvard Educational Review, vol. 57, No. 1, (pp. 1-23).

[4]Shulman, L. S. (1986) .Those who understand: Knowledge growth in teaching. Educational Researcher, vol. 15, No. 2, (pp. 4-14).

[5]Mazibe, E. N., Coetzee, C. \& Gaigher, E. (2018). A comparison between reported and enacted pedagogical content knowledge (pck) about graphs of motion. Research in Science Education, https://doi.org/10.1007/s11165-018-9718-7.

[6]Erwin, E. \& Rustaman, N. Y. (2017). Understanding of prospective physics teachers students toward pedagogical content knowledge on optical geometry materials. Journal of Physics: Conference Series, vol. 895, (pp. 012102).

[7]Buabeng, I., Conner, L. \& Winter, D. (2016). Physics teachers' views on their initial teacher education. Australian Journal of Teacher Education, vol. 41, No. 7, (pp. 36-55).

[8]Ma, C. \& Liu, T. (2016). Professional literacy structure of pre-service physics teachers in china. International Journal of Engineering Applied Sciences and Technology, vol. 1, No. 10, (pp. 1-4).

[9]Blömeke, S., Buchholtz, N., Suhl, U. \& Kaiser, G. (2014) .Resolving the chicken-or-egg causality dilemma: The longitudinal interplay of teacher knowledge and teacher beliefs. Teaching and Teacher Education, vol. 37, (pp. 130-139).

[10]Alonzo, A. C. \& Kim, J. (2018). Affordances of videobased professional development for supporting physics teachers' judgments about evidence of student thinking. Teaching and Teacher Education, vol. 76, (pp. 283-297).

[11]Shah, L., Hao, J., Rodriguez, C. A., Fallin, R., Linenberger-Cortes, K., Ray, H. E. \& Rushton, G. T. (2018). Analysis of praxis physics subject assessment examinees and performance: Who are our prospective physics teachers? Physical Review Physics Education Research, vol. 14, No. 1, (pp. 010126).

[12]Tao, X., Jiliang, S. \& Chongde., L. (1999). The reform of teacher education from the perspective of teachers' knowledge structure. Higher Normal Education Research, No. 6, (pp. 12-14).

[13]Asikainen, M. A. \& Hirvonen, P. E. (2010). Finnish cooperating physics teachers' conceptions of physics teachers' teacher knowledge. Journal of Science Teacher Education, vol. 21, No. 4, (pp. 431-450).

[14]Krzywacki, H. (2017). Physics teacher knowledge aimed in pedagogical studies in finland and in south korea. EURASIA Journal of Mathematics, Science and Technology Education, vol. 13, No. 1, (pp. 201-202).

[15]Abd-El-Khalick, F. (2012). Teaching with and about nature of science, and science teacher knowledge domains. Science \& Education, vol. 22, No. 9, (pp. 2087-2107). 
International Journal of Engineering Applied Sciences and Technology, 2019 Vol. 4, Issue 3, ISSN No. 2455-2143, Pages 55-61

Published Online July 2019 in IJEAST (http://www.ijeast.com)

[16]Shengquan, Y. \& Qi, W. (2019). Analysis of collaborative path development of "AI+Teachers". Audio-visual education research, vol. 40, No. 4, (pp. 14-22). 